\title{
Bone marrow manifestation of plasmablastic transformation of chronic lymphocytic leukemia: a case report
}

\author{
Chelsea Hayes • Yao Ma • Maria Delioukina • \\ Serhan Alkan • Qin Huang
}

Received: 21 August 2014 / Accepted: 18 September 2014 /Published online: 15 October 2014

(C) Springer-Verlag Berlin Heidelberg 2014

\begin{abstract}
Transformation of low-grade B cell lymphoproliferative disorders to high-grade lymphomas is a well-described occurrence. Transformation is considered the natural course of disease and is thought to result from a clonal evolution. Chronic lymphocytic leukemia/small lymphocytic lymphoma (CLL/SLL) most commonly transforms to diffuse large B cell lymphoma, a process known as Richter transformation. Plasmablastic transformation of CLL/SLL is extremely rare. Here, we report a unique case of characteristic plasmablastic lymphoma (PBL) and CLL/SLL manifesting concurrently in the bone marrow of a patient with previously diagnosed CLL/ SLL. The intimately admixed components represent two distinct morphologic and immunophenotypic populations of PBL and CLL/SLL. Cytogenetic/FISH analysis suggests a clonal evolution. Thus, PBL transformation may represent a new category of Richter transformation.
\end{abstract}

Keywords Bone marrow · Chronic lymphocytic leukemia/ small lymphocytic lymphoma · Epstein-Barr virus ·

Plasmablastic lymphoma $\cdot$ Richter transformation

$\begin{array}{ll}\text { Abbreviations } \\ \text { BTK } & \begin{array}{l}\text { Bruton's tyrosine kinase } \\ \text { CLL/SLL }\end{array} \\ & \begin{array}{l}\text { Chronic lymphocytic leukemia/small } \\ \text { lymphocytic lymphoma }\end{array} \\ \text { DLBCL } & \text { Diffuse large B cell lymphoma } \\ \text { EBV } & \text { Epstein-Barr virus } \\ \text { FISH } & \text { Fluorescence in situ hybridization } \\ \text { PBL } & \text { Plasmablastic lymphoma }\end{array}$

C. Hayes $\cdot$ Y. Ma $\cdot$ M. Delioukina $\cdot$ S. Alkan $\cdot$ Q. Huang $(\square)$ Department of Pathology and Laboratory Medicine1 and Hematology/Oncology2, Cedars-Sinai Medical Center, 8700 Beverly Blvd., Los Angeles, CA 90048, USA

e-mail: qin.huang@cshs.org

\section{Introduction}

Transformation of low-grade B cell lymphoproliferative disorders to high-grade lymphomas is a well-described occurrence and takes place in 25 to $35 \%$ of patients with follicular lymphoma and 2 to $8 \%$ of patients with chronic lymphocytic leukemia/small lymphocytic lymphoma (CLL/SLL) [1]. Transformation is usually considered to be the natural course of disease and is thought to result from a clonal evolution. Low-grade CLL/SLL most commonly transforms to diffuse large B cell lymphoma, a process well known as Richter transformation, although rare cases of transformation to other high-grade lymphomas, including rare plasmablastic lympho$\mathrm{ma}(\mathrm{PBL})$, have also recently been reported [2-6].

PBL is a clinically aggressive, immunodeficiencyassociated high-grade lymphoma predominantly occurring in extranodal locations [1]. It is characterized by a diffuse proliferation of large, immunoblastic cells with plasmacytic immunophenotypic features and has a strong association with Epstein-Barr virus (EBV) infection [1]. Here, we report a unique case of plasmablastic transformation occurring in a bone marrow biopsy from a patient with previously diagnosed CLL/SLL.

\section{Case report}

A 75-year-old male presented to the emergency department with fatigue, fever, abdominal pain, nausea, and vomiting. The patient's past medical history includes refractory CLL/ SLL, autoimmune hemolytic anemia, hypertension, and a prior stroke. The CLL/SLL, which was initially diagnosed in 1999, was lambda restricted with immunohistochemical expression of CD20, PAX5, CD5, CD23, and CD43. Prior fluorescence in situ hybridization (FISH) studies showed monosomy 13 and deletion of 13q14.3. Of note, the patient's 
most recent bone marrow biopsy was approximately 2 months prior to the current presentation and showed persistent CLL/SLL with no evidence of large cell transformation. The patient was most recently treated with ibrutinib, which was stopped approximately 2 weeks prior to presentation secondary to fatigue.

The patient was found to be pancytopenic with a complete blood count at presentation showing: WBC, $2.5 \mathrm{k} / \mu \mathrm{L} ; \mathrm{RBC}$, $3.2 \mathrm{M} / \mu \mathrm{L} ; \mathrm{Hgb}, 8.9 \mathrm{~g} / \mathrm{dL} ; \mathrm{HCT}, 28.5 \%$; MCV, $89.1 \mathrm{fL} ; \mathrm{MCH}$, 27.8 pg; MCHC, $31.2 \%$; RDW, $18.6 \%$; platelet, $38 \mathrm{k} / \mu \mathrm{L}$; and MPV, $13.0 \mathrm{fL}$ with an automated differential of polymorphonuclear leukocytes, $50 \%$; immature granulocytes, $4 \%$; lymphocytes, $41 \%$; monocytes, $5 \%$; eosinophils, $0 \%$; and basophils, $0 \%$. Serum protein electrophoresis studies showed an $\mathrm{M}$ protein of $0.13 \mathrm{~g} / \mathrm{dL}$ migrating as IgM and lambda light chain on immunofixation. A CT scan revealed extensive lymphadenopathy involving the chest, abdomen, and pelvis. An "acute leukemia" was suspected clinically. A posterior iliac crest bone marrow biopsy was performed, and the procedure concluded without complication.

\section{Materials and methods}

Peripheral blood and bone marrow aspirates were stained with a Wright-Giemsa stain. The bone marrow core specimen was fixed in $10 \%$ neutral buffered formalin and processed routinely. Paraffin-embedded blocks were stained with hematoxylin and eosin. Immunohistochemical analysis was carried out with a Bond III Instrument (Leica Microsystems, Buffalo Grove, IL) and a BenchMark ULTRA system (Ventana, Tucson, AZ), according to the manufacturer's instructions, using the following primary antibodies: CD20, CD3, CD10, BCL6, CD30, CD5, PAX5, c-MYC, CD138, kappa, lambda, BCL2, BCL1, CD79a, hemoglobin, CD15, HHV8, P53, MUM1, CD56, Ki-67, and EBV-LMP. Additionally, Epstein-Barr encoding RNA (EBER) in situ hybridization was performed.

Flow cytometric analysis was performed on bone marrow samples using the FC 500 Flow Cytometer (Beckman Coulter, Fullerton, CA) per the manufacturer's protocol. FISH analysis was done on the bone marrow aspirate sample with Abbott Molecular probes specific for the ATM gene (11q22.3), the centromere of chromosome 12, the 13q14.3/q34 regions, and the TP53 gene (17p13.1). FISH for c-MYC rearrangement (8q24) was performed on an aspirate clot section. Conventional cytogenetic analysis was performed on metaphase cells from two cultures using G-banding at or below the 450 band level of resolution.

\section{Results}

The bone marrow biopsy specimen consisted of peripheral blood, bone marrow aspirate material, and one 4-mm needle core biopsy. The peripheral blood smear showed a population of mature-appearing small lymphocytes, characterized by round nuclei, clumpy chromatin, and scant cytoplasm, consistent with features characteristic of CLL/SLL. Circulating blasts and large lymphoid cells were not identified.

The bone marrow aspirate smears (Fig. 1a) showed a background of decreased trilineage hematopoiesis and many small lymphocytes with features characteristic of CLL/SLL, similar to those seen in the peripheral blood. Additionally, a substantial population of large, polymorphic lymphoid cells, characterized by central or peripheral nuclei, multiple prominent nucleoli, and moderate amounts of dark blue cytoplasm, were identified. Numerous apoptotic bodies and mitotic forms were also noted.

Histologic sections of the bone marrow core biopsy showed an $80 \%$ hypercellular marrow with near total replacement by the atypical lymphoid populations previously noted (Fig. 1b). In the majority of the specimen, the small and large lymphoid cells were intimately admixed with one another and did not form discrete or segregated populations; however, aggregates of large lymphoid cells were seen in some areas.

Immunohistochemically, the small lymphocytes were positive for CD20, CD5, and dim CD23, similar to the CLL/SLL immunophenotype previously reported. The large, polymorphous lymphoid cells were positive for CD138 (Fig. 1c), CD79a, MUM1 and showed strong lambda light-chain restriction by immunohistochemistry (Fig. 1d) and were completely negative for CD20 (Fig. 1e), PAX-5, and CD5. EBV staining by EBER in situ hybridization was positive in nearly all of the large cells (Fig. 1f); EBV-LMP was positive only in rare large cells, and HHV8 was negative. CD56 was completely negative in both cell populations. Interestingly, immunohistochemical analysis with antibodies against P53 and c-myc highlighted only the large plasmablastic cells and not the small CLL/SLL cells. The proliferation index in the plasmablastic component was estimated to be approximately $90 \%$ by Ki- 67 staining.

Flow cytometric immunophenotyping of the bone marrow aspirate showed a lambda-restricted B cell population that was positive for $\mathrm{CD} 20, \mathrm{CD} 5$, and CD23, consistent with CLL/ SLL. An obvious monoclonal large cell population was not identified, which was thought to be due to the large lymphocytes inability to survive the flow cytometric process.

FISH studies showed the presence of an abnormal hyperdiploid clone, including four copies of chromosomes 11 and 12, and deletion of 13q14.3 in $30 \%$ of cells (Fig. 2a), as well as a relative loss of the TP53 gene in $16 \%$ of cells (Fig. 2b). FISH for MYC rearrangement was negative. Similar to the FISH results, karyotype analysis revealed an abnormal hyperdiploid clone, including relative loss of chromosomes 13 and $17 p$ (Table 1). Since deletion of $13 q$ was initially identified in the patient's original CLL/SLL, the current chromosomal karyotypic abnormalities may suggest a clonal evolution.

Based on morphology, immunohistochemistry, and cytogenetic studies, the diagnosis was hypercellular marrow with 


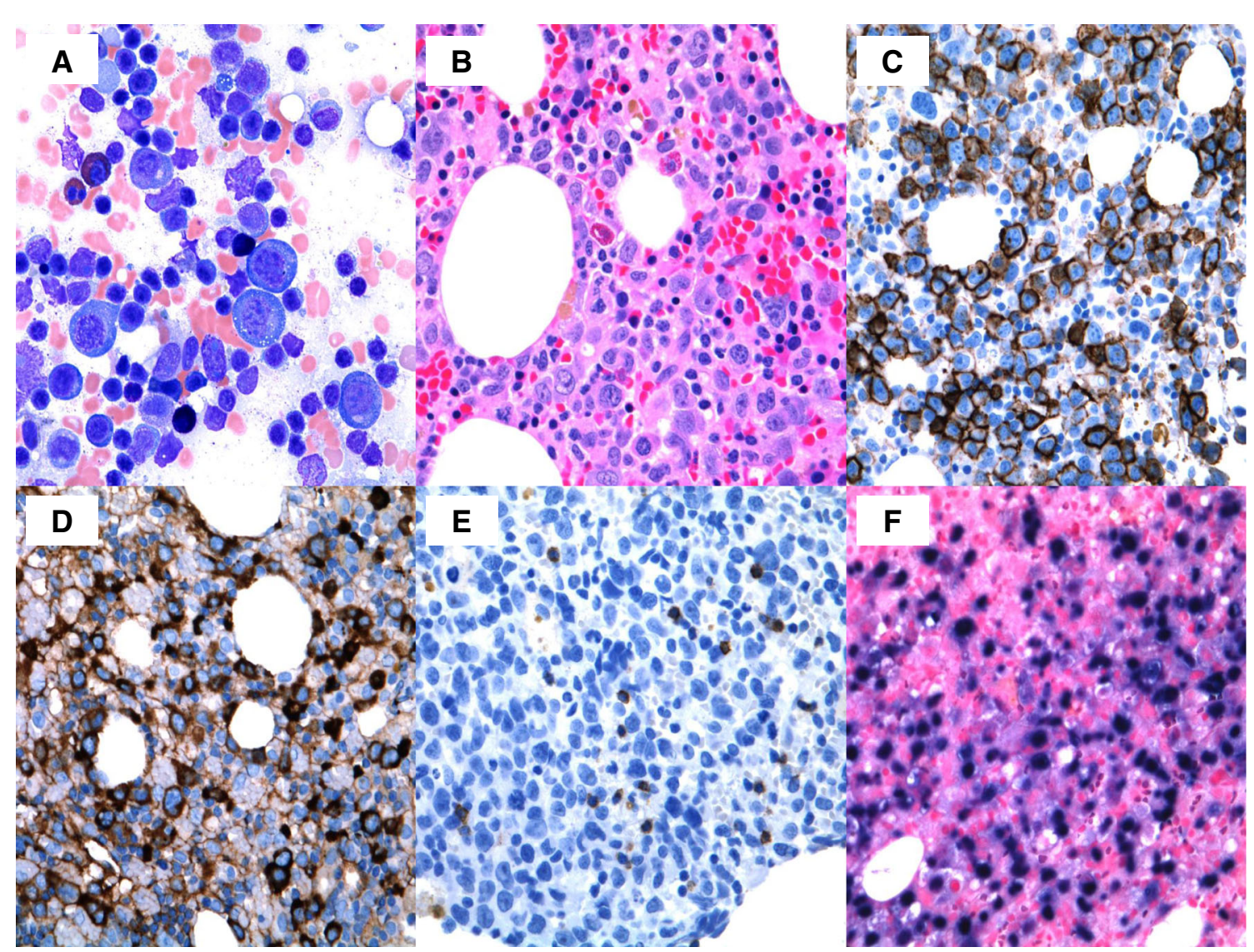

Fig. 1 Bone marrow manifestation of CLL/SLL with PBL transformation. Bone marrow aspirate smear (a) and hematoxylin and eosin clot section (b) showing admixed small (CLL/SLL) and large lymphoid cell (PBL) infiltration. The immunohistochemistry showing large lymphoid cells are positive for CD138 (c), with strong cytoplasmic lambda lightchain expression (d), and are negative for CD20 (e). Additionally, EBV in situ hybridization is strongly positive (f) involvement by both EBV-positive PBL and persistent CLL/ SLL. The cytogenetic and FISH analysis provided support for plasmablastic transformation of CLL/SLL by clonal evolution. The patient received no additional therapy and was discharged home on hospice care.

\section{Discussion}

Low-grade chronic lymphocytic leukemia/small lymphocytic lymphoma (CLL/SLL) most commonly transforms to diffuse large B cell lymphoma, a process known as Richter
Fig. 2 FISH analysis. Left cell showing deletion of 13q14.3, orange; two copies of centromere 12, green; and two copies of 13q34, aqua (a). Right cell showing deletion of TP53, orange; and two copies of ATM, green $(\mathbf{b})$

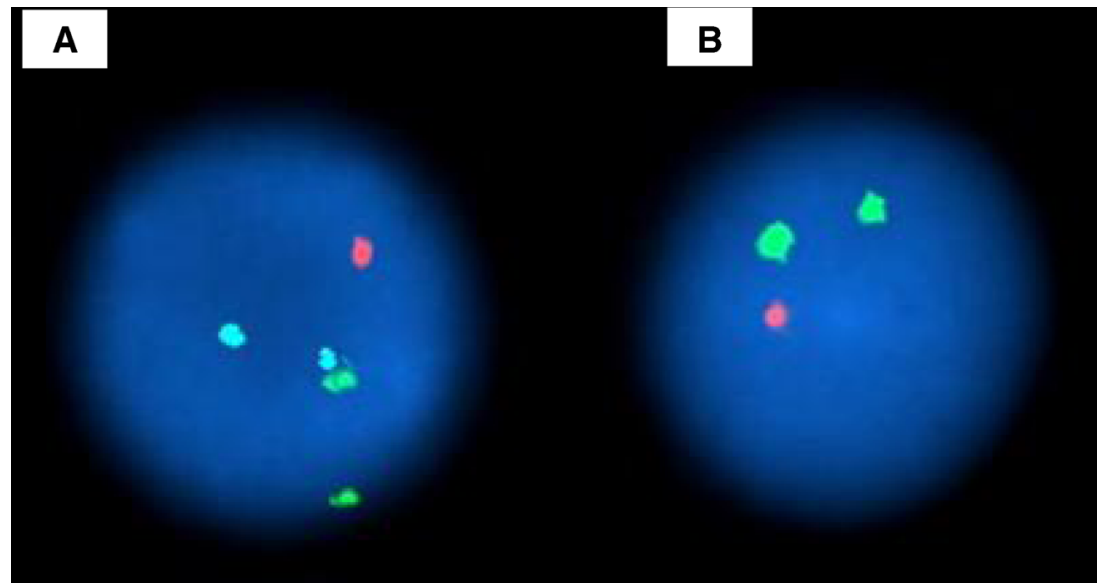


Table 1 CLL/SLL and PBL cytogenetic and FISH studies

\begin{tabular}{|c|c|c|}
\hline \multicolumn{2}{|l|}{ CLL/SLL } & \multirow{2}{*}{ 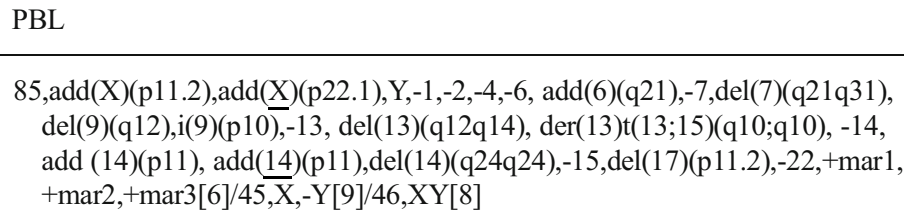 } \\
\hline Cytogenetic studies & $\begin{array}{l}\text { 45, X,-Y[10]/45, idem, del(5)(q22q25)[1]/46, } \\
\quad X Y, \operatorname{del}(13)(\mathrm{q} 12 \mathrm{q} 14)[1] / 46, X Y[8]\end{array}$ & \\
\hline FISH & $\begin{array}{l}\text { - Positive for deletion of } 13 \mathrm{q} 14.3 \\
\text { - Positive for monosomy } 13 \\
\text { - Negative for abnormalities in chromosomes } \\
\quad 11,12 \text {, and } 17\end{array}$ & $\begin{array}{l}\text { - Positive for deletion of } 13 \mathrm{q} 14.3 \\
\text { - Positive for monosomy } 13 \\
\text { - Positive for deletion of } 17 \mathrm{p} \\
\text { - Four copies of chromosomes } 11 \text { and } 12 \\
\text { - Negative for MYC rearrangement }\end{array}$ \\
\hline
\end{tabular}

transformation. Direct transformation from CLL/SLL to plasmablastic lymphoma (PBL) is extremely rare but few cases have been reported [2-6].

PBL is a high-grade B cell lymphoma classically occurring in the oral cavity of HIV-positive patients, but may also present in other extranodal sites. Bone marrow involvement by PBL is extremely rare. While the majority of PBL cases arise de novo, rare cases of secondary PBL, such as development after low-grade B cell lymphoma via direct transformation, may occur [2-6]. Immunophenotypically, PBL is classically negative for B cell markers (CD20), positive for plasma cell markers (CD138, CD79a, and MUM1), shows strong light-chain expression, and has a strong association with HIV and EBV [1, 7]. While some features of our case are unusual for PBL, including bone marrow manifestation and lack of HIV infection, the morphologic features and immunophenotype of the large lymphoid cell population were typical for PBL. Unlike the current case, the majority of previously described low-grade B cell lymphomas transforming to PBL appeared to have no association with EBV infection. The rare cases of PBL transformation that were reported to be associated with EBV infection all had a history of prior chemotherapy [6]. Additionally, some studies report MYC rearrangement positivity in PBL transformation cases $[2,6]$. However, MYC translocations were not identified by either FISH or karyotype analysis in the current case.

Plasma cell myeloma was also considered as a differential diagnosis; however, the cellular morphology, absence of lytic lesions in the bone, presence of a very low level of IgM monoclonal protein on serum electrophoresis studies, as well as the strong EBV positivity, argues against this diagnosis. Additional high-grade lymphomas associated with EBV, such as diffuse large B cell lymphoma (DLBCL) of the elderly and DLBCL associated with chronic inflammation, were also considered; however, the negativity of all B cell associated antigens makes these entities unlikely.

The exact mechanism driving Richter transformation is unclear, and development of high-grade lymphoma is thought to occur in one of two ways, either direct transformation from the pre-existing CLL/SLL or development of a concurrent, unrelated neoplasm [8]. It has been proposed that several factors play a role in transformation of CLL/SLL into highgrade lymphoma, including medical therapy with purine analogues [9-13], immunosuppression [14], and EBV infection $[13,15,16]$. It is noted that our patient had a long history of CLL/SLL and was recently treated with ibrutinib, a potent Bruton's tyrosine kinase (BTK) inhibitor, prior to the plasmablastic transformation. This observation is interesting and may raise questions about the relationship between ibrutinib exposure and plasmablastic transformation. BTK is well known to be critical to the growth and survival of B cells. By blocking BTK function and B cell receptor signaling, ibrutinib is assumed to have direct impact on the patient's immunofunction. A previous clinical trial targeting refractory CLL/SLL by ibrutinib demonstrates only few side effects with rare persistent lymphocytosis and no evidence of large cell transformation or clonal evolution within the series studied [17]. Following our observation in this patient, it may be interesting for future large-scale clinical trials to investigate PBL transformation following ibrutinib administration.

Although rare cases of PBL transformation have previously been described, only few reports show evidence of direct transformation from pre-existing CLL/SLL [6].

The current case suggests that the two morphologically and immunophenotypically distinct populations identified appear to be clonally related. In fact, the PBL and CLL/SLL tumor cells infiltrate the bone marrow in an admixed fashion and exhibit identical lambda light-chain restriction. Furthermore, cytogenetic and FISH studies performed on the current specimen show the presence of an abnormal hyperdiploid clone with complex abnormalities, which include the monosomy 13/deletion of 13q14.3 identified in the prior CLL/SLL before transformation. In addition to previously identified abnormalities, the current specimen also shows deletion of 17p (TP53 gene) and polyploid chromosomal abnormalities, suggesting a clonal evolution. Additionally, the positive P53 and c-myc expression by immunohistochemistry observed only in the large PBL cells support this observation. Although the admixed nature of the small and large lymphoid cells in the current specimen make it difficult to assess whether these 
changes are present in the PBL or in the background CLL/ SLL, our FISH studies clearly demonstrate the complex chromosomal abnormalities that are present in the large PBL cells.

In summary, we present a unique case of classic PBL and CLL/SLL present concurrently in the bone marrow of a patient with previously diagnosed CLL/SLL. The evidence of possible clonal evolution by cytogenetic/FISH analysis is suggestive of direct transformation of the two distinct pathologic entities. Low-grade B cell lymphoma, such as CLL/SLL, transformation to PBL may represent a new category of Richter transformation.

Conflict of interest The authors declare that they have no conflict of interest.

\section{References}

1. Swerdlow S, Campo E, Harris N et al (2008) WHO classification of tumours of haematopoietic and lymphoid tissues. IARC Press, Lyon

2. Pan Z, Xie Q, Repertinger S, Richendollar BG, Chan WC, Huang Q (2013) Plasmablastic transformation of low-grade CD5+ B-cell lymphoproliferative disorder with MYC gene rearrangements. Hum Pathol 44:2139-2148

3. Robak T, Urbanska-Rys H, Strzelecka B, Krykowski E, Bartkowiak J, Blonski JZ, Kordek R, Warzocha K (2001) Plasmablastic lymphoma in a patient with chronic lymphocytic leukemia heavily pretreated with cladribine (2-Cda): an unusual variant of Richter's syndrome. Eur J Haematol 67:322-327

4. Ramalingam P, Nayak-Kapoor A, Reid-Nicholson M, JonesCrawford J, Ustun C (2008) Plasmablastic lymphoma with small lymphocytic lymphoma: clinico-pathologic features, and review of the literature. Leuk Lymphoma England 49:1999-2002

5. Foo WC, Huang Q, Sebastian S, Hutchinson CB, Burchette J, Wang E (2010) Concurrent classical Hodgkin lymphoma and plasmablastic lymphoma in a patient with chronic lymphocytic leukemia/small lymphocytic lymphoma treated with fludarabine: a dimorphic presentation of iatrogenic immunodeficiency-associated lymphoproliferative disorder with evidence suggestive of multiclonal transformability of B cells by Epstein-Barr virus. Hum Pathol 41:1802-1808

6. Martinez D, Valera A, Perez NS, Sua Villegas LF, Gonzalez-Farre B, Sole C, Gine E, Lopez-Guillermo A, Roue G, Martinez S, Sant F, Warzocha K, Robak T, Czader M, Villamor N, Colomo L, Campo E,
Martinez A (2013) Plasmablastic transformation of low-grade B-cell lymphomas: report on 6 cases. Am J Surg Pathol 37:272-281

7. Delecluse HJ, Anagnostopoulos I, Dallenbach F, Hummel M, Marafioti T, Schneider U, Huhn D, Schmidt-Westhausen A, Reichart PA, Gross U, Stein H (1997) Plasmablastic lymphomas of the oral cavity: a new entity associated with the human immunodeficiency virus infection. Blood 89:1413-1420

8. Matolcsy A, Inghirami G, Knowles DM (1994) Molecular genetic demonstration of the diverse evolution of Richter's syndrome (chronic lymphocytic leukemia and subsequent large cell lymphoma). Blood 83:1363-1372

9. Bernasconi P, Paulli M, Orlandi E, Perfetti V, Giardini I, Zibellini S, Vanelli L, Tenore AM, Algarotti A, Boni M, De Amici M, Brusamolino E, Lazzarino M (2007) Development of a Richter syndrome with a monoclonal component from a true B-cell chronic lymphocytic leukemia (B-CLL) treated with fludarabine. Ann Hematol 86:619-622

10. Cohen Y, Da'as N, Libster D, Amir G, Berrebi A, Polliack A (2002) Large-cell transformation of chronic lymphocytic leukemia and follicular lymphoma during or soon after treatment with fludarabinerituximab-containing regimens: natural history- or therapy-related complication? Eur J Haematol 68:80-83

11. Fong D, Kaiser A, Spizzo G, Gastl G, Tzankov A (2005) Hodgkin's disease variant of Richter's syndrome in chronic lymphocytic leukaemia patients previously treated with fludarabine. $\mathrm{Br} \mathrm{J}$ Haematol 129:199-205

12. Shields DJ, Byrd JC, Abbondanzo SL, Lichy JH, Diehl LF, Aguilera NI (1997) Detection of Epstein-Barr virus in transformations of lowgrade B-cell lymphomas after fludarabine treatment. Mod Pathol 10: $1151-1159$

13. Thornton PD, Bellas C, Santon A, Shah G, Pocock C, Wotherspoon AC, Matutes E, Catovsky D (2005) Richter's transformation of chronic lymphocytic leukemia. The possible role of fludarabine and the Epstein-Barr virus in its pathogenesis. Leuk Res 29:389-395

14. Kunicka JE, Platsoucas CD (1988) Defective helper function of purified T4 cells and excessive suppressor activity of purified T8 cells in patients with B-cell chronic lymphocytic leukemia T4 suppressor effector cells are present in certain patients. Blood 71:15511560

15. Ansell SM, Li CY, Lloyd RV, Phyliky RL (1999) Epstein-Barr virus infection in Richter's transformation. Am J Hematol 60:99-104

16. de Leval L, Vivario M, De Prijck B, Zhou Y, Boniver J, Harris NL, Isaacson P, Du MQ (2004) Distinct clonal origin in two cases of Hodgkin's lymphoma variant of Richter's syndrome associated with EBV infection. Am J Surg Pathol 28:679-686

17. Woyach JA, Smucker K, Smith LL et al (2014) Prolonged lymphocytosis during ibrutinib therapy is associated with distinct molecular characteristics and does not indicate a suboptimal response to therapy. Blood 123:1810-1817 